\title{
Standardization of serum neutralization assay of Japanese encephalitis virus (Nakayama NIH strain) on BHK-21 (Cl-13) cell line
}

\author{
S. SINGH ${ }^{1}$, M. SHARMA2 S. KUMAR², D. GOWAL ${ }^{2}$
}

${ }^{1}$ Department of Biotechnology, G.B. Pant Engineering College, Pauri-Garhwal; ${ }^{2}$ Central Research Institute, Kasauli (H.P.), India

Received March 24, 2015; revised April 15, 2015; accepted July 30, 2015

\begin{abstract}
Summary. - Potency testing of Japanese encephalitis (JE) vaccine has been a complex process since its inception. To overcome difficulties encountered therein, an alternative assay, serum neutralization test (SNT), using Baby Hamster Kidney 21 cell line, has been standardized. The antibody response generated against JE vaccine was quantified and the assay was found to be sensitive and specific enough with significant accuracy and precision. On analysis of cell count, a cell concentration of $1.5 \times 10^{4}$ was selected as the optimum, since concentrations above and below this resulted in problems of confluent monolayer formation and incomplete monolayer formation. Incubation time has also been standardized for measuring cytopathic effect (CPE). Out of the four different time points selected, $90 \mathrm{~min}$ was found to be adequate for $50 \%$ reduction in the amount of CPE. The accuracy of SNT assay is explained in terms of fiducial limits at 95\% level. Inter- and intra-assay reproducibility testing was also performed. A comparison of potency of JE vaccine by plaque reduction neutralization test (PRNT) and SNT method was conducted and it was found that SNT can be a reliable approach for estimating the potency of JE vaccine. The results of this study throw a light on the utility of SNT assay for the potency estimation of JE vaccine in routine practice.
\end{abstract}

Keywords: Japanese encephalitis; single stranded virus; potency testing; plaque reduction neutralization test; serum neutralization test

\section{Introduction}

Japanese encephalitis (JE) is a serious public health problem with significant mortality in children and old people in many countries of Asia. Worldwide, nearly 3 billion people are believed to be at risk of JE and approximately 20,000 clinical cases resulting in 6,000 deaths are reported annually (WHO Position paper weekly record, 2006, 2007). JE virus is the most important cause of viral encephalitis in eastern and southern Asia, with 30,000-50,000 cases reported an-

E-mail: siddharth.sharma.bce11@iitbhu.ac.in; phone: +917897720422 .

Abbreviations: $\mathrm{CCID}_{50}=$ cell culture infectious dose $50 \%$; $\mathrm{CEFB}=$ chick embryo fibroblast $\mathrm{CPE}=$ cytopathic effect $\mathrm{CV}=$ coefficient of variation; $\mathrm{FD}$ = freeze dried; JE = Japanese encephalitis; $\mathrm{LV}=$ limit of variation; PRNT = plaque reduction neutralization test; $\mathrm{SNT}=$ serum neutralization test; $\mathrm{TC}=$ tissue culture; $\mathrm{WHO}=$ World Health Organization nually (Solomon and Vaughn, 2002), although this may be a considerable underestimate because of inadequate surveillance and reporting. Of these cases, about $25-30 \%$ are fatal and $50 \%$ result in permanent neuropsychiatric sequelae (Burke and Leake, 1988), complete recovery occurs in only one third of patients (WHO recommendation, 2007). Most infections are asymptomatic, with estimates of the ratio of symptomatic to asymptomatic infection ranging from 1 in 25 to 1 in 1,000 , the variation depending on many factors, including endemicity, exposure to mosquitoes, pre-existing antibodies to Flaviviruses and virus strain differences (Solomon and Vaughn, 2002; Mackenzie and Gubler, 2004; Solomon and Winter, 2007). The control of JE is based largely on three interventions: mosquito control, avoiding human exposure and immunization. Mosquito control has been less than effective and suffers from the lack of research into new pesticides. Eliminating human exposure to infected mosquitoes, when it is feasible, is only a short-term solution. Thus, immunization is the only effective method for long-term 
protection (Mackenzie and Gubler, 2004). There are 3 types of inactivated vaccines currently used in the world: i) mouse brain-derived, purified vaccine, which is based on either the Nakayama-NIH or Beijing-1 [P-1] strains; ii) primary hamster kidney (PHK) cell-derived, purified vaccine, based on the Beijing-3 [P-3] strain; and iii) Vero-cell derived purified vaccine based on the Beijing-3 [P-3] strain. Newer Vero cell-derived inactivated JE vaccines under development use either Beijing-1 or SA14-14-2 strains as virus seeds (WHO revision recommendation 2007).

In India, formalized mouse brain JE vaccine has been in use since 1987. India has produced an effective and safe freeze-dried (FD) JE vaccine from mouse brain source using Nakayama NIH JE virus strain, which has been found to be highly potent, safe and stable. Efficacy and safety of this vaccine has been well established (Rao Bhau et al., 1988). The presence of neutralizing antibodies provides the best evidence available that protective immunity has likely been established. There are several methodologies for determining functional antibody responses to the virus, which include hemagglutination-inhibition (HI), ELISA or immunofluorescent antibody (IFA) tests (WHO revision recommendation, 2007). PRNT is the most commonly used method for detection of neutralizing antibody. It is the most reliable, sensitive and specific assay but quite lengthy, laborious and technically demanding procedure. The substrate used here is a primary culture of chick embryo fibroblast (CEFB) cells. A large number of embryonated eggs as well as trained staff are required to carry out the assay. Because of the complicated nature of preparing CEFB cell culture, the present study deals with standardizing the SNT using an established cell line (such as BHK-21), which could reduce labor and be simple to perform. The WHO recommends the use of BHK-21 cells in the quality testing of JE vaccines such as in the virus-inactivation test and also for potency estimation (WHO technical report, 1988). Thus, an attempt has been made to propagate JEV in BHK-21 (clone-13) cell line and to develop a novel assay for potency testing of the JE vaccine.

\section{Materials and Methods}

JE virus strain. JE virus strain used for the study was the Nakayama N.I.H. (passage level $\mathrm{Ad}_{29} \mathrm{Sm}_{10}$ ) supplied by Dr. Akira, Oya, Deputy Director General, National Institute of Health, Tokyo, Japan. The stock virus (1:10) was obtained from JE (QC) Division, CRI Kasauli, HP (Under Ministry of Health \& Family Welfare, Govt. of India) at passage level $\mathrm{Ad}_{29} \mathrm{Sm}_{10} \mathrm{Sm}_{3}$ and was prepared as described in Minimum Requirement for JE Vaccine, Government of Japan (1986), Indian Pharmacopoeia (1996) and WHO revision recommendation (2007).

Test samples. The sera samples from mice immunized with three different batches of freeze-dried (FD) JE vaccine (Code A, B \& C) used in the study were obtained from JE (QC) Division (stored at $-20^{\circ} \mathrm{C}$ ).
One of these batches (i.e. A) was already established as an in-house reference standard for the potency estimation of the FD JE vaccine.

Cell line. BHK-21(Cl-13) cell line was obtained from Central Drugs Laboratory/National Control Laboratory, CRI, Kasauli, at passage level 87 and was certified to be free from Mycoplasma and other adventitious agents. The cells were revived as per the standard procedure.

Cell concentration. BHK-21 cell monolayer grown in plastic tissue culture flask $\left(75 \mathrm{~cm}^{2}\right.$, Greiner Bio-One) was detached by TrypsinEDTA (1x, SIGMA) and the cells were suspended in cell growth medium i.e. Eagle's Minimum Essential Medium (SIGMA) supplemented with 5\% FBS (GIBCO). The cell count was done using hemocytometer. Different cell numbers ( $1 \times 10^{4}$ to $2.5 \times 10^{4}$ ) were added to the wells of sterile 96-well TC plates (Greiner Bio-One) and incubated at $36 \pm 1^{\circ} \mathrm{C}$, $5 \% \mathrm{CO}_{2}$. Observations were made after overnight incubation. The cell count, which gave a nearly complete monolayer formation after overnight incubation, was selected for the study.

Virus titration and calculation of working dilution of virus for SNT assay. The cell culture infectious dose $50 \%\left(\mathrm{CCID}_{50}\right)$ titer of the JE virus was calculated as per the method of Reed \& Muench (Lennette, 1964) and Payment \& Trudel (Payment and Trudel, 1993). Briefly, the JE stock virus (1:10) was diluted ten-fold serially $\left(10^{-2}\right.$ to $\left.10^{-7}\right)$ followed by half-log dilutions $\left(10^{-7.5}\right.$ to $\left.10^{-11.5}\right)$ in chilled medium (EMEM (1x, Sigma) with 5\% FBS (GIBCO)). $100 \mu$ of virus dilution from $10^{-7.0}$ to $10^{-11.5}$ was added to each of the column wells from 1-10 of a sterile 96 -well TC plate. The $11^{\text {th }}$ and $12^{\text {th }}$ columns were kept as cell controls. $100 \mu$ of pre-standardized BHK-21 cell suspension (containing app. 15,000 cells) was added to each well followed by incubation at $36 \pm 1^{\circ} \mathrm{C}, 5 \% \mathrm{CO}_{2}$ for $4-5$ days. The $\mathrm{CCID}_{50}$ titer was calculated by observing the pattern of CPE in the wells. For confirmation, the assay was repeated twice. The working dilution of JE virus for SNT assay was kept at $100 \mathrm{CCID}_{50}$.

Optimization of neutralization time and incubation period for SNT. Serial two-fold dilutions of the test serum sample, prepared in chilled EMEM (1x, Sigma) with 5\% FBS (GIBCO) in four 96well TC plates (Greiner Bio-One), were reacted against a dose of $100 \mathrm{CCID}_{50}$ of the virus for variable time periods, viz. 30, 60, 90 and $120 \mathrm{~min}$. After completion of the desired time period, $100 \mu \mathrm{l}$ of BHK-21 cells containing app. $1.5 \times 10^{4}$ cells were dispensed into each plate followed by incubation at $36 \pm 1^{\circ} \mathrm{C}, 5 \% \mathrm{CO}_{2}$. The optimum neutralization time period of JE virus was determined by observing the extent of CPE in different plates. The time period sufficient for $50 \%$ neutralization of virus was selected for SNT assay. The incubation time period, i.e. time taken for appearance of final results, was decided by incubating the TC plates (containing virus-serum mixture and $\mathrm{BHK}-21$ cells at $36 \pm 1^{\circ} \mathrm{C}, 5 \% \mathrm{CO}_{2}$ ) and observing for appearance of CPE in virus control wells on $3^{\text {rd }}, 4^{\text {th }}, 5^{\text {th }}$ and $6^{\text {th }}$ day and comparing them with healthy cell controls.

Serum neutralization assay for estimation of 50\% neutralization end point. Heat inactivated sera samples were diluted two-fold serially $\left(10^{-1.3}\right.$ to $\left.10^{-3.7}\right)$ in EMEM (1x, Sigma) with 5\% FBS (GIBCO) in a 96-well TC plate (Greiner Bio-One). To each well (from $1^{\text {st }}$ to $9^{\text {th }}$ column), containing $50 \mu$ l of diluted serum sample, $50 \mu \mathrm{l}$ of JE 
virus $\left(100 \mathrm{CCID}_{50}\right)$ prepared as mentioned earlier was added. The plate contents were mixed by shaking the plate gently and kept at $36 \pm 1^{\circ} \mathrm{C}, 5 \% \mathrm{CO}_{2}$ for $90 \mathrm{~min}$ (optimum) for virus neutralization, followed by addition of $100 \mu \mathrm{l}$ of BHK-21 cell suspension containing approximately $1.5 \times 10^{4}$ cells.

Virus control. The $10^{\text {th }}$ column-wells of the plate were kept as virus control containing $50 \mu \mathrm{l}$ of EMEM (1x) with $5 \%$ FBS, $50 \mu$ of JE virus $\left(100 \mathrm{CCID}_{50}\right)$ suspension and $100 \mu \mathrm{l}$ of BHK-21 cells.

Cell control. The $11^{\text {th }}$ and $12^{\text {th }}$ column-wells were kept as normal cell controls containing $100 \mu \mathrm{l}$ of EMEM (1x) with 5\% FBS and $100 \mu \mathrm{l}$ of BHK-21 cell suspension. The plate was incubated at $36+1^{\circ} \mathrm{C}, 5 \%$ $\mathrm{CO}_{2}$ and after 4 days (optimized incubation time) of incubation, final results were recorded. 50\% neutralization end point of sera samples were calculated by using Reed and Muench formula (1964).

The above-mentioned sera samples were also evaluated in parallel for neutralization antibody response by the conventional PRNT assay, which is a routine procedure in JE (QC) division. The results obtained by the two methods were evaluated statistically.

Assay validation study. To validate the SNT accuracy, precision and degree of correlation were studied as per the guidelines of ICH (ICH Topic Q 2 (R1)), WHO recommendation $(1992,1997)$ and Eurachem (1998). Accuracy is the closeness of the results obtained by multiple determinations of same sample. For this the SNT was performed on three different occasions on a single batch of JE vaccine (in-house reference standard; code-A). Precision is the closeness of agreement between the values obtained in an assay. It is expressed as the coefficient of variation (\% CV). Both inter-assay and intra-assay precisions were evaluated as per the requirements of WHO recommendation $(1992,1997)$ and Eurachem (1998) guidelines. Intra-assay precision (repeatability) is the \% CV of multiple determinations of a single sample in a single test run. It expresses the precision under the same operating conditions over a short interval of time; inter-assay precision (also called intermediate precision) measures the $\% \mathrm{CV}$ for multiple determinations of a single sample, in several assay runs in the same laboratory (WHO recommendation, 1997).

\section{Results}

\section{Cell concentration}

The first parameter of the study was to standardize the cell count of BHK-21 cells to be used per well of the 96-well TC plate. The cell count that would result in a complete monolayer formation after an overnight incubation and maintain viability throughout the test duration was decided to be the acceptance criterion. In this study it was observed that the cell counts below $1.5 \times 10^{4}$ per well could not form a complete monolayer after overnight incubation while, on the other hand, cell count equal to or above $2.0 \times 10^{4}$ per well resulted in confluent monolayer formation that was not suitable for the assay. Hence $1.5 \times 10^{4}$ cells per well was selected to be the optimum count for the assay.

\section{Neutralization time period}

Of the four time periods (30, 60, 90 and $120 \mathrm{~min})$ selected for the interaction between the JE virus and the specific antibodies for the purpose of complete neutralization of the former, the $90 \mathrm{~min}$ was found to be adequate. On comparing the extent of neutralization in the four plates, the first plate, after 30 min of interaction, showed JE virus specific CPE (rounding and detachment of cells) in almost all the wells. The extent of CPE was comparatively lower in the $2^{\text {nd }}$ plate (60 min neutralization time). The effect of increment in the time period above $60 \mathrm{~min}$ and up to $90 \mathrm{~min}$ resulted in almost $50 \%$ reduction in the amount of CPE positivity. No significant difference was observed in the extent of virus neutralization by increasing the neutralization time beyond $90 \mathrm{~min}$.

\section{Optimization of incubation period for SNT}

The optimum incubation time for the serum neutralization test was found to be four days, as the cell control remained healthy till this time and also the virus control wells showed almost 100\% CPE at the selected virus concentration on $4^{\text {th }}$ day.

\section{Accuracy}

The accuracy of SNT is explained in terms of fiducial limits at $95 \%$ level. The assay was performed on three different occasions on a single batch of JE vaccine (in-house reference standard; code-A). The mean neutralizing antibody titer $\log _{10}$ of $N=6$ samples per assay was calculated. Each potency value was in between the upper and lower fiducial limits (Table 1).

Table 1. Validation of SNT accuracy

\begin{tabular}{|c|c|c|c|c|}
\hline Assay & Mean Nt-Ab titer $\log _{10}$ & Standard deviation & Upper fiducial limit ${ }^{\mathrm{a}}$ & Lower fiducial limit \\
\hline I & 2.662 & 0.0307 & 2.687 & 2.638 \\
\hline II & 2.656 & 0.0283 & 2.679 & 2.634 \\
\hline III & 2.652 & 0.0311 & 2.677 & 2.627 \\
\hline
\end{tabular}

${ }^{\mathrm{a}}$ Upper fiducial limit $=$ Mean +1.96 (Standard error). ${ }^{\mathrm{b}}$ Lower fiducial limit $=$ Mean -1.96 (Standard error). Nt-Ab titer $=$ neutralizing antibody titer. 
Table 2. Validation of intra-assay precision of SNT

\begin{tabular}{|c|c|c|c|c|c|c|}
\hline $\begin{array}{l}\text { JE vaccine } \\
\text { batch No. }\end{array}$ & Vial No. & $\log _{10} \mathrm{Nt}-\mathrm{Ab}$ titer & Mean & SD & CV (\%) & $\mathbf{L V}^{\star}(\%)$ \\
\hline \multirow[t]{5}{*}{ A } & 1 & 2.688 & 2.658 & 0.0314 & 1.18 & 1.69 \\
\hline & 2 & 2.650 & & & & \\
\hline & 3 & 2.613 & & & & \\
\hline & 4 & 2.688 & & & & \\
\hline & 5 & 2.650 & & & & \\
\hline \multirow[t]{5}{*}{ B } & 1 & 2.650 & 2.673 & 0.057 & 2.13 & 2.24 \\
\hline & 2 & 2.613 & & & & \\
\hline & 3 & 2.650 & & & & \\
\hline & 4 & 2.763 & & & & \\
\hline & 5 & 2.688 & & & & \\
\hline \multirow[t]{5}{*}{$\mathrm{C}$} & 1 & 2.688 & 2.718 & 0.0488 & 1.80 & 2.49 \\
\hline & 2 & 2.763 & & & & \\
\hline & 3 & 2.650 & & & & \\
\hline & 4 & 2.762 & & & & \\
\hline & 5 & 2.725 & & & & \\
\hline
\end{tabular}

$\mathrm{JE}=$ Japanese encephalitis vaccine; $\mathrm{Nt}-\mathrm{Ab}$ titer = neutralizing antibody titer; $\mathrm{SD}=$ standard deviation; $\mathrm{CV}=$ coefficient of variation. ${ }^{*} \mathrm{Limit}$ of variation $(\mathrm{LV})$ is defined as $\pm \%$ highest individual deviation from the Mean value and was calculated as: $\operatorname{LV}(\%)=[($ mean of titer - lowest titer $) /$ mean of titer $] \mathrm{x} 100$.

Table 3. Validation of inter-assay precision of SNT

\begin{tabular}{|c|c|c|c|c|c|c|c|c|c|}
\hline \multirow{2}{*}{$\begin{array}{l}\text { JE vaccine } \\
\text { batch No. }\end{array}$} & \multirow{2}{*}{ Vial No. } & \multicolumn{4}{|c|}{ Neutralizing antibody titer } & \multirow{2}{*}{ Mean } & \multirow{2}{*}{ SD } & \multirow{2}{*}{ CV (\%) } & \multirow{2}{*}{$\mathbf{L V}^{\star}(\%)$} \\
\hline & & Day 1 & Day 2 & Day 3 & Day 4 & & & & \\
\hline \multirow[t]{2}{*}{ A } & I & 2.613 & 2.650 & 2.688 & 2.650 & 2.650 & 0.0306 & 1.16 & 1.41 \\
\hline & II & 2.650 & 2.688 & 2.688 & 2.725 & 2.688 & 0.0306 & 1.14 & 1.40 \\
\hline \multirow[t]{2}{*}{ B } & I & 2.613 & 2.650 & 2.688 & 2.650 & 2.679 & 0.0641 & 2.39 & 2.45 \\
\hline & II & 2.763 & 2.613 & 2.650 & 2.688 & 2.660 & 0.0359 & 1.35 & 1.76 \\
\hline \multirow[t]{2}{*}{$\mathrm{C}$} & I & 2.650 & 2.688 & 2.613 & 2.725 & 2.669 & 0.0483 & 1.81 & 2.10 \\
\hline & II & 2.65 & 2.763 & 2.763 & 2.688 & 2.716 & 0.0564 & 2.08 & 2.43 \\
\hline
\end{tabular}

$\mathrm{SD}=$ standard deviation. $\mathrm{CV}=$ coefficient of variation. The average CV for the batches tested $=1.65 \%$; the average $\mathrm{LV}$ for the batches tested $=1.92 \%$. ${ }^{\star} \mathrm{Limit}$ of variation $(\mathrm{LV})$ is defined as $\pm \%$ highest individual deviation from the Mean value and was calculated as: $\mathrm{LV}(\%)=[(\mathrm{mean}$ of inverse of titer - lowest titer) / mean of inverse of titer] x 100 .

\section{Intra-assay precision (Reproducibility)}

Intra-assay precision was established by calculating coefficient of variation $(\mathrm{CV})$ and limit of variation (LV). The CV of the three batches (A, B, and C) of JE vaccine ( 5 vials each) was found to be $1.18 \%, 2.13 \%$ and $1.80 \%$, while the $\mathrm{LV}$ was $1.69 \%, 2.24 \%$ and $2.49 \%$, respectively, indicating nearly $2.5 \%$ variation in the results (Table 2).

\section{Inter-assay precision (Repeatability)}

For SNT inter-assay precision, the given three batches of $\mathrm{JE}$ vaccine were titrated on four different time periods, i.e. day $1,2,3$ and 4 . Less than $2.5 \%$ variation in the potency titers was observed on all four days. The average CV and LV were calculated to be $1.65 \%$ and $1.92 \%$, respectively, for the inter-assay precision (Table 3 ).

Comparison of JE vaccine potency by PRNT and SNT methods

To establish the degree of correlation between the conventional PRNT assay and SNT assay, potency of the JE vaccine in-house reference standard (A) was evaluated by both the methods and the results were analyzed statistically using Graphpad prism online software (Table 4). The comparison of the results obtained from the two assays shows that intra-assay variation for PRNT assay is lower that for SNT, still the difference is not statistically significant. Further, a fairly high degree of correlation $(r=0.869)$ has been observed between the two assays, indicating that 
Table 4. Comparison of neutralizing antibody titers $(\log 10)$ of JE vaccine (in-house reference standard) by PRNT and SNT assay

\begin{tabular}{lcc}
\hline \multirow{2}{*}{ S. No. } & \multicolumn{2}{c}{ Nt-Ab titer $\left(\log _{10}\right)$} \\
\cline { 2 - 3 } & PRNT assay & SNT assay \\
\hline 1 & 2.288 & 2.688 \\
2 & 2.288 & 2.650 \\
3 & 2.267 & 2.613 \\
4 & 2.309 & 2.688 \\
5 & 2.267 & 2.650 \\
6 & 2.309 & 2.725 \\
7 & 2.267 & 2.688 \\
8 & 2.309 & 2.650 \\
9 & 2.204 & 2.538 \\
10 & 2.225 & 2.575 \\
\hline Mean \pm SD & $2.273 \pm 0.036$ & $2.647 \pm 0.057$ \\
\hline CV & 1.573 & 2.159 \\
\hline Coefficient of & \multicolumn{2}{c}{$r=0.869, \mathrm{r}^{2}=0.7544$} \\
correlation &
\end{tabular}

$\mathrm{Nt}-\mathrm{Ab}$ titer $=$ neutralizing antibody titer.

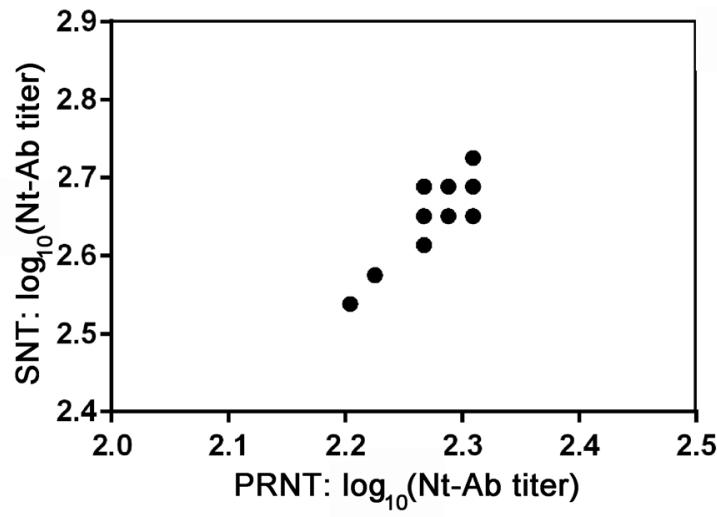

Fig. 1

Correlation between SNT and PRNT assay

SNT can be a reliable approach for estimating the potency of JE vaccine (Fig. 1).

\section{Discussion}

The quality testing (mainly the potency testing) of JE vaccine is a complex procedure. To the best of our knowledge, much work has not been done till date to address this problem and determination of efficacy of the vaccine still relies only on PRNT using CEFB, which is a primary cell culture system and is not free from its own inherent problems. Development of alternatives approaches for the potency estimation of JE vaccine is need of hour to replace the conventional test, which is a complex, lengthy and laborious procedure. The main objective remains to develop an assay that is less complicated, economical and less laborious.

In the present study, an attempt was made to standardize SNT to measure the potency of JE vaccine using BHK-21 cell line (a continuous type cell culture system). Further, the assay was validated on the basis of different variables such as accuracy, precision, degree of correlation etc. as recommended (ICH Topic Q2 (R1); WHO recommendation, 1992, 1997; Eurachem Guide, 1998). Different methods such as hemagglutination-inhibition, ELISA or immunofluorescent antibody tests have been previously reported to deliver satisfactory results for the detection of antibodies in the serum (WHO recommendation, 2007). However, none of these methods have been adopted in routine practice. In the present study, SNT was used for the quantitation of antibody response generated against JE vaccine. On the basis of the results obtained in this study, SNT was found to have a significant accuracy and precision, indicating that SNT can be easily adopted for the potency estimation of JE vaccine. Results of SNT were also compared with PRNT assay. A high degree of correlation was observed between both methods, suggesting SNT as a competent alternative. Moreover, the reduced cost, labor and less complexity of SNT would definitely attract other laboratories to adopt this procedure in their routine practice.

\section{Conclusion}

In the light of results obtained from this study it can be concluded that SNT using BHK-21 cells can be viewed as a reliable method and, possibly, it can stand well as an alternative approach for the potency estimation of the JE vaccine. However, a more controlled study will throw more light on this aspect and will pave the path towards adoption of this method.

\section{References}

Burke DS, Leake CJ (1988): Japanese encephalitis. In Monath TP (Ed.): The Arboviruses: Epidemiology and Ecology. Vol. 3. CRC, Boca Raton, Florida, pp. 63-92.

Eurachem G (1998): The fitness for purpose of analytical methods. A laboratory guide to method validation and related topics. In The Eurachem Guide 1st Internet version.

ICH Topic Q 2 (R1): Validation of Analytical Procedures: note for guidance on validation of analytical procedures: Text and methodology CPMP/ICH/381/95.

Indian Pharmacopoeia (1996): JE Vaccine Human (Mouse Brain). pp. 416-417.

Lennette EH (1964): General principles underlying laboratory diagnosis of Viral and Rickettsial infections. In Lennette EH, Schmidt NJ (Ed.): Diagnostic Procedures for Viral and Rickettsial Diseases. New York: American Public Health Association, Inc., pp. 1-67. 
Mackenzie JS, Gubler DJ, Petersen LR (2004): Emerging flaviviruses: the spread and resurgence of Japanese encephalitis, West Nile and dengue viruses. Nature Med. (Suppl.) 10, S98-1S09. http://dx.doi.org/10.1038/nm1144

Ministry of Health and Welfare, Government of Japan, Tokyo (1986): Minimum Requirement of JE Vaccine.

Payment P, Trudel M (1993): Isolation and identification of viruses. Methods Techniques Virol. 3, 19-38.

Rao Bhau LN, Singh G, Gowal D, Saxena SN, Kobayashi M, Oya A, Yoshioka I (1988): Safety and efficacy of JE vaccine produced in India. Indian J. Med. Res. 88, 301-307.

Solomon T, Winter PM (2004): Neurovirulence and host factors in flavivirus encephalitis-evidence from clinical epidemiology. Arch. Virol. (Suppl.) 18, 161-170. http://dx.doi. org/10.1007/978-3-7091-0572-6 14

Solomon T, Vaughn DW (2002): Pathogenesis and clinical features of Japanese encephalitis and West Nile virus infections. Curr. Top. Microbiol. Immunol. 267, 171-194. http:// dx.doi.org/10.1007/978-3-642-59403-8 9

WHO (2006): Japanese encephalitis vaccines: WHO Position Paper. Weekly Epidemiological Record. 81, 331-340.
WHO (2007): Expert Committee on Biological Standardization, Proposed Revision Recommendations for Japanese Encephalitis Vaccine (Inactivated) for Human Use. WHO/ BS/07.20644.

WHO (2007): Annex-1, Technical Report Series 963 (revised 2007).

WHO (2007): Expert Committee On Biological Standardization, Proposed Revision Recommendations For Japanese Encephalitis Vaccine (Inactivated) For Human Use. WHO/ BS/07.20644.

WHO (1988): Requirement for JE Vaccine (Inactivated) for Human Use. Technical Report Series 771, 131-151.

WHO (2007): Expert Committee on Biological Standardization, Proposed Revision Recommendations for Japanese Encephalitis Vaccine (Inactivated) for Human Use. WHO/ BS/07.20644

WHO (1997): Validation of analytical assays. In A WHO Guide to GMP Requirements. Part 2: Validation. WHO/VSQ/97.02.

WHO (1992): Validation of analytical procedure used in the examination of pharmaceutical materials. In WHO Expert Committee on Specification of Pharmaceutical Preparations. Technical Report Series 823, 117-121. 